\title{
ASPECTOS CLÍNICOS E FISIOPATOLÓGICOS DE OSTEOSSARCOMA EM CÃES
}

Recebido: $14 / 02 / 2014$

JÚNIOR GARDINALLI, Benedito ${ }^{1}$; MARTELLI, Anderson ${ }^{2}$.

Aceito: 30/12/2014

${ }^{1}$ Pós-Graduação em Produção e Reprodução de Bovinos - Instituto de Pós-Graduação Qualittas, Médico
Veterinário da Secretaria de Agricultura e Meio Ambiente de Itapira - SP; ${ }^{2}$ Pós-Graduação em Laboratório
Clinico - Universidade Estadual de Campinas, Professor da Faculdade Mogiana do
Estado de São Paulo - Mogi Guaçu -SP.

\section{RESUMO}

$\mathrm{O}$

Osteossarcoma (OSA) é um tumor ósseo maligno caracterizado pela formação de tecido ósseo neoplásico com crescimento rápido e invasivo. Dentre os tumores ósseos primários o OSA é o mais comum devido à proliferação de células mesenquimatosas primitivas e malignas com a produção de matriz osteóide. Sua etiologia permanece desconhecida, porém existem evidências de OSA desenvolverem-se em ossos que sustentam maiores pesos e em sítios adjacentes de fechamento tardio, através da sensibilização celular por fatores mitogênicos, sítios prévios relacionados a implantes ortopédicos metálicos, radiações ionizantes, mutações genéticas e infecções virais. Seu diagnóstico está baseado no histórico clínico do animal, exames físicos, de imagens e histopatológicos. Tratamentos recentes baseiam-se em quimioterapias e cirurgias poupadoras de membros, resultando em um prognóstico mais favorável. O presente trabalho apresenta como objetivo uma revisão da literatura especializada sobre os aspectos clínicos e fisiopatológicos de OSA em cães. Para a composição da revisão foi realizado um levantamento bibliográfico nas bases de dados Scielo, portal de Periódicos da Coordenação de Aperfeiçoamento de Pessoal de Nível Superior (CAPES), e a busca de dados no Google Acadêmico de artigos científicos nacionais e internacionais e livros acadêmicos. O OSA causa considerável número de mortes, assim um diagnóstico correto e um tratamento apropriado pode melhorar a sobrevida desses animais, levando ao declínio dos índices de mortalidade que vêm sendo observados.

Palavras-chave: Osteossarcoma. Cães. Tumor. Tratamento. 


\section{INTRODUÇÃO}

$\mathrm{Na}$ oncologia veterinária, o osteossarcoma (OSA) é definido como um tumor mesenquimal primário maligno cujas células cancerosas produzem matriz osteóide, é um tumor ósseo que ocorre frequentemente em cães, afetando principalmente animais de grande porte e de meia idade (KLEINER; SILVA, 2003). Representa 80-85\% dos tumores ósseos e 5-6\% de todos os tumores, possuindo maior risco de incidência em cães com peso acima de 36 kg (KLEINER; SILVA, 2003; SILVEIRA et al., 2005). Faz parte de um grupo heterogêneo de neoplasias malignas que afetam a formação de osso ou tecido mesenquimal, sendo caracterizado pela diversidade de aspectos histológicos e de comportamento clínico-biológico (MARTELLI et al., 2007; SOARES et al., 2005), muito agressivo e com um crescimento rápido (BASTOS et al., 1999), altamente metastático e com grande predileção pelo pulmão, em torno de $90 \%$ dos casos (SILVEIRA et al.,2005).

Estudos demonstram que em cães a região metafisária de ossos longos é o sitio primário mais comum de ocorrência do OSA (ETTINGER; FELDMAN, 2000), sendo os membros torácicos mais acometidos que os pélvicos, na proporção de 2:1, a extremidade distal do rádio e a proximal do úmero são os locais de maior ocorrência (DALECK et al., 2002). Dentre as raças mais acometidas estão: Pastor Alemão, Rottweiler, Dogue Alemão, Dobermann, São Bernardo, Setter Irlandês, Golden Retriever e Fila Brasileiro. Em machos a incidência é maior do que em fêmeas, entretanto, o OSA no esqueleto axial acomete mais as fêmeas do que os machos (DALECK et al., 2002; TEIXEIRA et al., 2010).

Quanto a sua localização, os tipos de OSA podem apresentar-se na forma central ou de superfície (BRASILEIRO FILHO, 2000). Para sua classificação, os dados são baseados nos padrões histológicos, sendo feita uma correlação dentre os subtipos de OSAs direcionando o prognóstico e a terapia aplicada (MEUTEN, 2002).

A classificação do OSA dentro das seis categorias (OSA pouco diferenciado, OSA osteoblástico, OSA condroblástico, OSA fibroblástico, OSA talangiectásico, OSA do tipo células gigantes) é determinada pelo padrão das secreções representativas do tumor, não havendo um padrão isolado dominante (MARTELLI et al., 2007). 
Seu diagnóstico não é fácil, exigindo íntima colaboração do clínico veterinário, radiologista e patologista, completado quando necessário por análises imuno-histoquímica, bioquímica, além de cintilografia óssea, tomografia computadorizada e ressonância magnética, possibilitando a avaliação da extensão da lesão dentro do osso e a invasão de partes moles, levando muitas vezes à amputação como forma de tratamento (BRASILEIRO FILHO, 2000; MARTELLI et al., 2007; WITTIG et al., 2002).

As principais manifestações dos sarcomas ósseos são o aumento de volume, dor e limitação dos movimentos, podendo ser descobertos pela ocorrência de fraturas ósseas patológicas ou em radiografia de rotina (BRASILEIRO FILHO, 2000).

Neste trabalho abordaremos de forma direta a etiologia, os aspectos clinicos, o prognóstico e tratamento do OSA.

\section{METODOLOGIA}

Para a composição da presente revisão foi realizado um levantamento bibliográfico entre os meses de junho a outubro de 2013 nas bases de dados Scielo, Lilacs, Portal de Periódicos da Coordenação de Aperfeiçoamento de Pessoal de Nível Superior (CAPES) e a busca de dados no Google Acadêmico de artigos científicos publicados até 2013 utilizando como descritores isolados ou em combinação: osteossarcoma, cães, tratamento e tumor, sendo realizada adicionalmente a consulta de livros acadêmicos para complementação das informações sobre os aspectos clínicos e fisiopatológicos de OSA em cães.

Para seleção do material, efetuaram-se três etapas. A primeira foi caracterizada pela pesquisa do material utilizado na revisão. A segunda compreendeu a leitura dos títulos e resumos desses artigos, visando uma maior aproximação e conhecimento, sendo excluídos os que não tivessem relação e relevância com o tema. Após essa seleção, buscaram-se os textos que se encontravam disponíveis na íntegra sendo estes, inclusos na revisão.

Os artigos selecionados e incluídos na pesquisa compreenderam ensaios clínicos, artigos originais, revisões e revisões sistemáticas. Como critérios de elegibilidade e inclusão dos artigos, analisaram-se a procedência e indexação das revistas, estudos que apresentassem 
dados referentes aos aspectos clínicos e fisiopatológicos de OSA em cães entre os anos de 1990 e 2013. Na leitura e avaliação, os artigos que apresentaram os critérios de elegibilidade foram selecionados e incluídos na pesquisa por consenso.

\section{FISIOPATOLOGIA DO OSTEOSSARCOMA}

Mutações genéticas são fundamentais para o desenvolvimento do OSA. Alterações no gene p53, podem impedir sua ação no estadiamento do crescimento tumoral e apoptose (COTRAN et al., 2000), incluindo assim o OSA entre os cânceres relacionados com a inativação de genes supressores de tumor (RUBIN; FARBER, 2002).

Muitos OSA desenvolvem-se em locais de maior crescimento ósseo, onde apresentam aumentada a atividade mitótica celular (COTRAN et al., 2000). Em cães, os sarcomas osteogênicos apresentam uma maior ocorrência nos membros torácicos, pois suportam $60 \%$ do peso corporal (MOORE, 2001).

Cães de grande porte são predispostos a pequenos e múltiplos traumas nas regiões metafisárias, local de uma maior atividade celular, conseqüentemente ocorre uma maior sensibilização destas células, iniciando a doença pela indução de sinais mitogênicos, aumentando assim a probabilidade de desenvolver uma linhagem celular mutante (DALECK et al., 2002).

Lesões ósseas benignas preexistentes estão associadas ao risco aumentado de OSA, incluindo a displasia fibrosa, infecções ósseas e infarto da medula óssea (RUBIN; FARBER, 2002). Embora a etiologia do OSA, de ocorrência natural em humanos e animais, permaneça desconhecida (DALECK et al., 2002; SIQUEIRA; CAVALCANTI, 1993), em cães, alguns pesquisadores levantam a hipótese de ser um agente viral, porem ainda não se isolou nenhum vírus responsável pelo surgimento de OSA canino (DALECK et al., 2002).

Outros fatores que podem estar associados ao desenvolvimento do OSA são o uso de implantes metálicos de fixação (DALECK et al., 2002; SIQUEIRA; CAVALCANTI, 1993) e em fraturas nas quais não se utilizou nenhuma forma de fixação interna (DALECK et al., 2002), displasia fibrosa, doença de Paget e osteomielite crônica (TOSSATO et al., 2002). 
A radiação ionizante pode também induzir o aparecimento do tumor em cães (DALECK et al., 2002). Numerosos hormônios e citocinas podem agir nos sítios de crescimento do osso estimulando excessivamente células tronco, podendo levar ao surgimento da neoplasia (DALECK et al., 2002).

Quanto aos aspectos macroscópicos e histopatológicos os OSAs podem variar muito, devido à capacidade que suas células apresentam em produzir quantidades diferentes de tecido osteóide, cartilaginoso ou fibroso (BRASILEIRO FILHO, 2000).

Quando a formação de tecido ósseo é intensa, o tumor é duro, esclerosante, em outros casos prevalece a osteólise óssea (osteolítico) e o tumor torna-se mole podendo ser encontradas cavidades com sangue e com frequência encontra-se aspectos diferentes no mesmo tumor (BRASILEIRO FILHO, 2000).

O tecido neoplásico pode invadir e romper o córtex ósseo, disseminando-se para a cavidade medular, elevar ou perfurar o periósteo ou crescer na epífise do osso alcançando o espaço articular (BRASILEIRO FILHO, 2000; JESUS-GARCIA et al., 1996; RUBIN; FARBER, 2002).

Macroscopicamente, os sarcomas ósseos são observados como tumores volumosos, brancoacinzentados e arenosos, apresentando áreas de hemorragia e degeneração cística (COTRAN et al., 2000). Nos casos mais avançados pode ocorrer ruptura da cortical com a formação de tumor em partes moles adjacentes à lesão óssea (CAMARGO; BAPTISTA, 2004; COTRAN et al., 2000).

A lise cortical é um achado frequente, podendo ser severa o suficiente para promover áreas de descontinuidade do córtex e ocasionar fraturas espontâneas (DALECK et al., 2002) e devido sua característica agressiva, pode causar comprometimento extracortical e, em alguns casos, propagação e destruição da região medular (JESUS-GARCIA et al., 1996).

Evidências radiológicas de destruição e formação óssea são características desse tumor. Com frequência o periósteo encontra-se elevado por formação de osso reativo e uma área triangular entre o córtex e o osso periosteal pode ser visualizada (Figura 1), sendo observado também um padrão de "raio-de-sol" (RUBIN; FARBER, 2002). O canal medular pode estar preenchido com um tecido homogêneo, róseo ou mesmo esbranquiçado e friável, sendo 
encontrado tecido de aspecto semelhante penetrando no córtex e formando grandes massas tumorais (SIQUEIRA; CAVALCANTI, 1993).

Nos tumores extra-esqueléticos observa-se radiograficamente como uma massa em regiões de tecidos moles, com calcificações, não associadas à erosão ou destruição óssea (LIMA et al., 2002). Já no OSA periosteal a característica mais importante é que essa neoplasia é constituída por tecido cartilaginoso, bem delimitada, com áreas de calcificação e ossificação junto à superfície externa do osso acometido. Neste caso o canal medular está usualmente poupado (DAVID et al., 2003).

Histologicamente, o OSA é um tumor mesenquimal maligno de células ósseas primitivas que se caracteriza pela produção de osteóide (LIMA et al., 2002; TOSSATO et al., 2002). Existem várias subclassificações histológicas, baseadas no tipo e quantidade de matriz óssea e nas características celulares: osteoblástico, condroblástico, fibroblástico, pouco diferenciado, talangiectásico (COSTA et al., 2001; DALECK et al., 2002) e do tipo células gigantes (MEUTEN, 2002) não sendo observado diferença em relação ao comportamento biológico entre esses subgrupos em cães (DALECK et al., 2002; NELSON; COUTO, 1998).

Devido à natureza multipotencial das células mesenquimais primitivas, a matriz envolvida nestes tumores pode conter variadas quantidades de tecido cartilaginoso, colágeno e osteóide, mesmo assim este tumor pode ser diagnosticado como OSA, refletindo desta forma o potencial maligno de tumores mesenquimais com potenciais osteogênicos (MEUTEN, 2002).

A presença de células mesenquimais malignas produzindo uma matriz de tecido fibroso ou cartilaginoso antes de osteóide, não exclui a possibilidade de OSA, especialmente se a lesão está num local de predileção conhecida (MEUTEN, 2002). Porém somente o OSA produz matriz osteóide (DALECK et al., 2002).

O exame de muitas secções de diferentes áreas do tumor pode ser necessário antes que a evidência da produção de osteóide seja detectada. A biópsia de lesões ósseas pode não se adequar ao tipo ou a qualidade para permitir que o patologista faça um diagnóstico definitivo (MEUTEN, 2002). 
O exame microscópico de baixo poder é importante para determinar o padrão e o comportamento do tumor, evidências de destruição e/ou difusão do tecido ósseo préexistentes na medula óssea ou a invasão do córtex. Invasões vasculares ou infiltrações de tecidos adjacentes podem ser aparentes (MEUTEN, 2002).

As células malignas coram-se para a fosfatase alcalina e osteonectina e com freqüência é observado focos de células de cartilagem malignas, nas áreas de lise ósseas, encontrando-se osteoclastos não neoplásicos na frente de avanço do tumor (RUBIN; FARBER, 2002).

A caracterização de OSA pode ser observada pela diferenciação de células mesenquimais primitivas e malignas em osteoblastos que por sua vez secretam matriz óssea (Figura1) (DALECK et al., 2002).
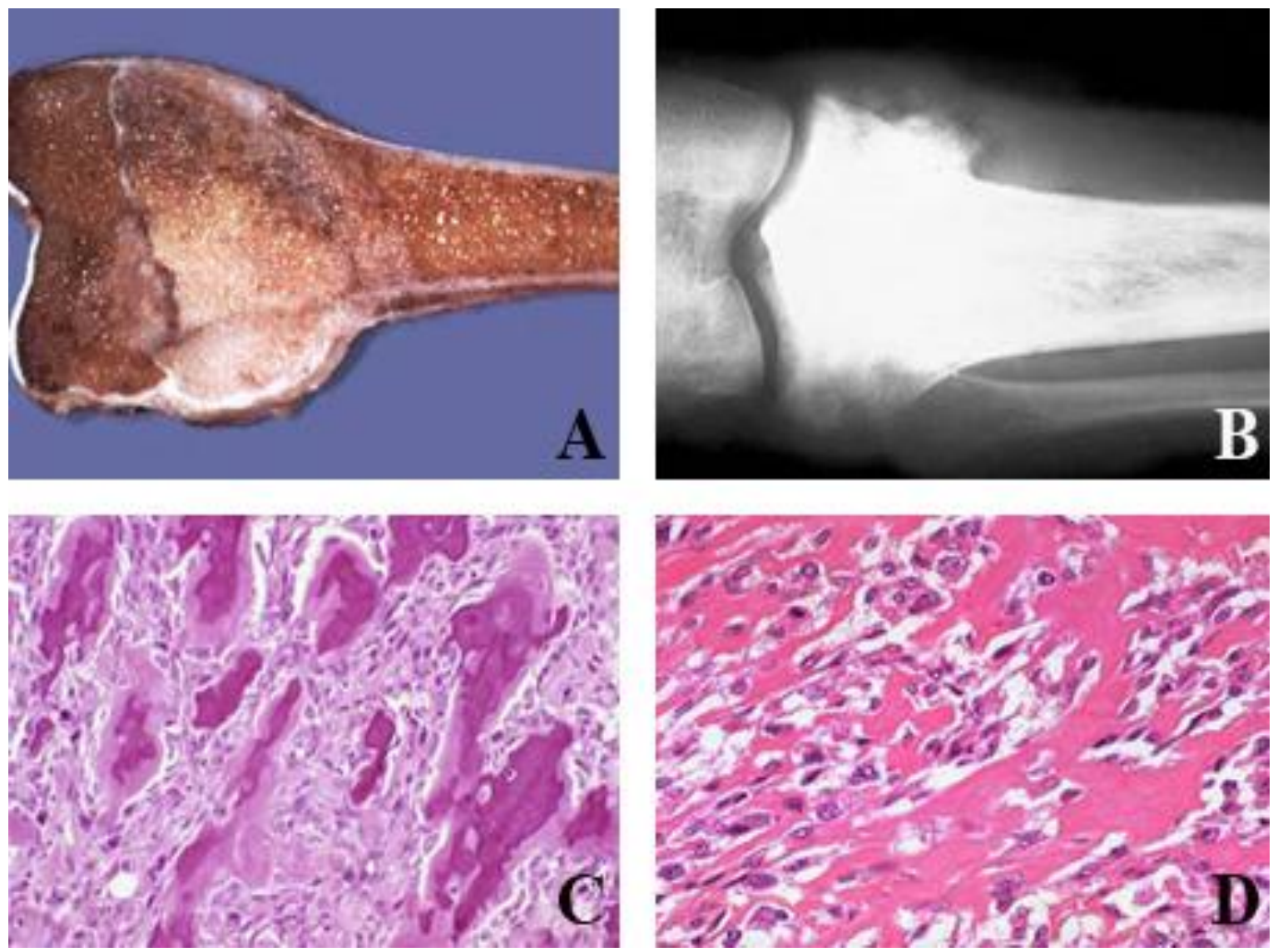

Figura 1 - Diferentes aspectos do OSA. Em A observa-se o crescimento do tumor com a elevação do periósteo. Em B observa-se triângulo de Codman mostrando a ruptura cortical. Em C e D são observados cortes histológicos corados com HE mostrando as espículas ósseas e a síntese de matriz osteóide (Extraído e modificado de COTRAN et al., 2000). 
Estes osteoblastos malignos podem variar de células em formato de haste, com um grau de pleomorfismo lembrando fibroblastos ou células arredondadas e ovais (MEUTEN, 2002; SOARES et al., 2005). Os núcleos celulares mostram-se hipercromáticos (MEUTEN, 2002; SIQUEIRA; CAVALCANTI, 1993) e com frequência são observadas figuras mitóticas (COSTA et al., 2001; COTRAN et al., 2000).

A forma e a quantidade de matriz osteóide é também altamente variável (COSTA et al., 2001; MEUTEN, 2002), células gigantes multinucleadas do tipo osteoclastos são frequentemente espalhadas pelo tumor (LIMA et al., 1998; MEUTEN, 2002), algumas vezes em números suficientes para sugerir um diagnóstico de tumor de células gigantes, mas a produção de osteóide pelas células tumorais pode permitir a exclusão desta opção (MEUTEN, 2002).

A classificação histológica de OSA a respeito de seu potencial maligno tem instigado os patologistas, pois a variação dos OSAs e mudanças microscópicas rápidas que podem ocorrer dentro do mesmo tumor, fazem esse exercício questionável. Nenhum sistema foi aceito como tendo um prognóstico significativo ou uma classificação amplamente usada para o OSA. Para sua classificação, os dados são baseados nos padrões histológicos, sendo feita uma correlação dentre os subtipos de OSAs direcionando o prognóstico e a terapia aplicada (MEUTEN, 2002).

As manifestações clínicas observadas nos osteossarcomas são massas tumorais de consistência firme (DAVID et al., 2003) e crescimento progressivo (COTRAN et al., 2000; COSTA et al., 2001), apresentando dores leves ou intermitentes nas áreas envolvidas. À medida que a dor torna-se mais intensa, a área envolvida torna-se edemaciada e sensível a palpação e o movimento da articulação adjacente fica limitado (RUBIN; FARBER, 2002). A dor é o principal sintoma presente nos pacientes portadores de lesões ósseas metastáticas, podendo ser causada diretamente pelo crescimento do tumor (CAMARGO; BAPTISTA, 2004), interrupção do periósteo e microfraturas (DALECK et al., 2002).

O aumento do volume local é observado somente em casos mais avançados, onde ocorre a ruptura da cortical com a formação de tumor em partes moles adjacentes à lesão óssea, podendo dessa forma identificar a tumoração (CAMARGO; BAPTISTA, 2004). 
Às vezes uma fratura súbita do osso é o primeiro sintoma do osteossarcoma (COTRAN et al., 2000; DALECK et al., 2002; DAVID et al., 2003), ocorrendo também o aumento da temperatura local (DAVID et al, 2003). Pode ser observado como sinais sistêmicos a hipercalcemia secundária à secreção de uma proteína semelhante ao PTH (paratormônio), podendo também aumentar a reabsorção de cálcio a nível renal (CAMARGO; BAPTISTA, 2004).

Em cães, além dos sintomas já citados, o OSA pode envolver a coluna vertebral provocando debilidade neurológica associada à compressão da medula espinhal (DALECK et al., 2002). O súbito avanço dos sinais de mielopatias podem ser resultantes de fraturas patológicas das vértebras (CAMARGO; BAPTISTA, 2004; DALECK et al.,2002), tremores, atrofia muscular por desuso, dificuldade em levantar-se, déficit esfincteriano, letargia e anorexia (DALECK et al., 2002), déficit neurológico e impotência sexual irreversíveis (CAMARGO; BAPTISTA, 2004). É importante frisar que esses tipos de lesões podem evoluir rapidamente causando em alguns casos paraplegia em questão de dias (CAMARGO; BAPTISTA, 2004).

O diagnóstico de lesões ósseas primárias como o OSA deve ser baseado na história clínica, exames físicos, achados radiológicos e cintilográficos, sendo a confirmação feita por biópsia óssea (DALECK et al., 2002), e exames histopatológicos (CAMARGO; BAPTISTA, 2004; MARTELLI et al., 2007).

A radiografia simples é a melhor ferramenta diagnóstica nas suspeitas dessas lesões ósseas metastáticas (CAMARGO; BAPTISTA, 2004), sendo importante para a avaliação da extensão do envolvimento ósseo e para distinguir neoplasias ósseas de outras condições não neoplásicas (DALECK et al., 2002). Este exame pode revelar lise cortical podendo promover descontinuidade do córtex causando fraturas espontâneas (DALECK et al., 2002), lesões osteolíticas (COSTA et al., 2001; DALECK et al., 2002) acompanhadas de elevação do periósteo e neoformação subperiosteal denominado de triângulo de Codmam, sendo sugestivas de neoplasias ósseas primárias (Figura 2) (COSTA et al., 2001). 


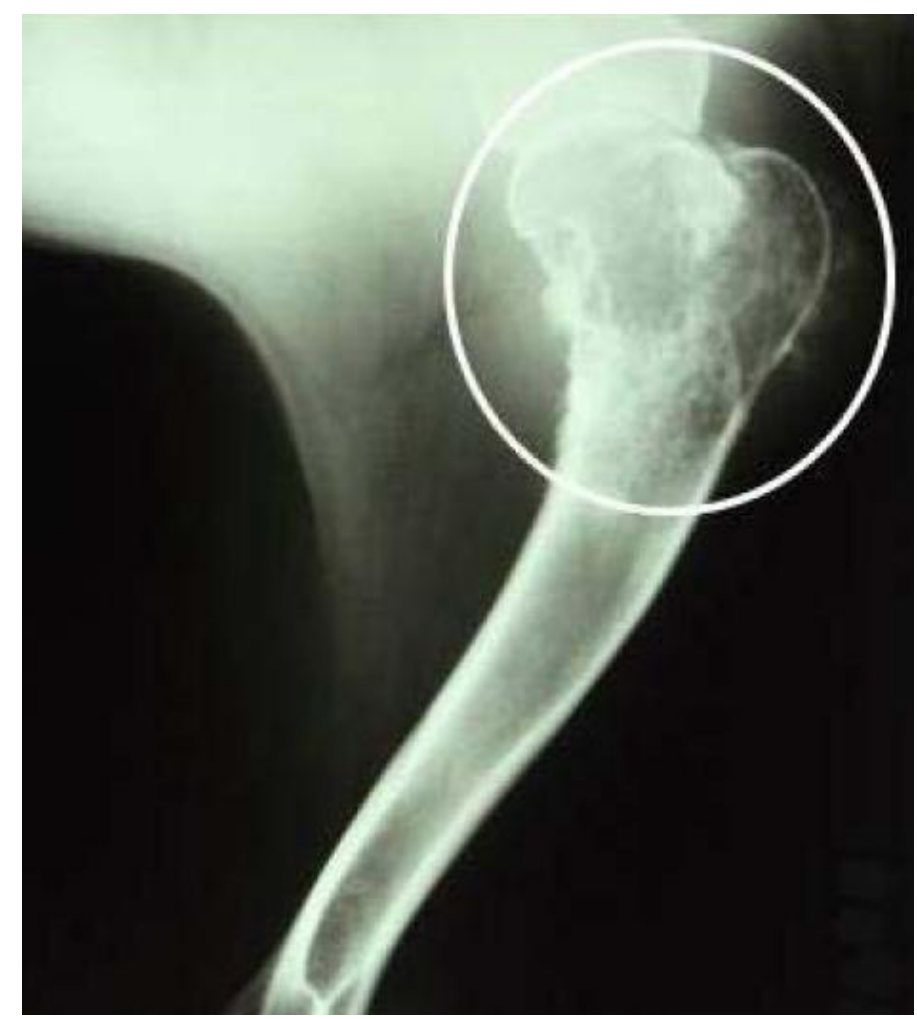

Figura 2 - Radiografia de membro anterior direito de uma fêmea da raça Pastor Alemão, antes da amputação, evidenciando o triângulo de Codman na região proximal do úmero (círculo) (Extraído e modificado de TEIXEIRA et al., 2010).

Radiografias torácicas devem ser realizadas com o objetivo de detectar doenças metastáticas (COSTA et al., 2001; DALECK et al., 2002). A citologia aspirativa com agulha fina (CAAF) é uma técnica menos invasiva e apresenta baixo custo, podendo propiciar o diagnóstico definitivo da afecção neoplásica (SHONUBI et al., 2004; STRAW et al., 1990). Kumar et al. (1993) observaram uma correlação significativa entre o diagnóstico citológico e o diagnóstico histopatológico em $94,1 \%$ dos casos de tumores ósseos.

Quando o diagnóstico citológico de OSA é inconclusivo, recomenda-se a confirmação histopatológica através da biópsia óssea e sua correta interpretação e análise das características histopatologicas podendo se chegar ao diagnóstico definitivo (DALECK et al., 2002). A biópsia óssea está mais bem indicada nos casos em que a lesão é única, ou quando há duvidas no diagnóstico, sendo que em 10 a 20\% dos casos não se consegue identificá-lo (CAMARGO; BAPTISTA, 2004). 
O local a ser feita a biopsia deve ser escolhido cuidadosamente, dando preferência à lesão central (DALECK et al., 2002). A biopsia pode ser realizada nessas lesões ósseas suspeitas preferencialmente por um cirurgião com experiência em tumores ósseos e uma vez confirmado o diagnóstico histológico de OSA é necessário determinar a extensão da doença através de exames específicos (RECH et al., 2004). Essa técnica apresenta como desvantagens o envolvimento de procedimentos cirúrgicos, riscos de complicações póscirurgia como hematomas, infecções, disseminação do tumor e fraturas patológicas (DALECK et al., 2002).

A cintilografia óssea no diagnóstico de OSA pode ser usada visando caracterizar o padrão de captação dos marcadores radioativos, tanto nas lesões primárias como nas metástases (LIMA et al., 2002). É uma técnica de elevada sensibilidade para a detecção de lesões esqueléticas, porem não é específica para a identificação de sítios ósseos tumorais. Qualquer região com atividade osteoblástica será identificada pela cintilografia óssea, incluindo a osteoartrite e infecções diversas (DALECK et al., 2002).

Outros meios diagnósticos, como a tomografia computadorizada (TC) oferece uma alta qualidade de imagens, com resoluções anatômicas excelentes e redução dos artefatos, apresentando assim grande importância no diagnóstico e planejamento do tratamento (DALECK et al., 2002), mostrando a extensão e a profundidade da lesão (TOSSATO et al., 2002). A ressonância magnética também pode ser indicada para o diagnóstico do tumor (DALECK et al., 2002), assim como a videolaparoscopia diagnóstica (MENDES et al., 2004). A arteriografia pode ser usada para o diagnóstico do padrão vascular do tumor e sua relação com as estruturas vasculares assim como para a infusão intra-arterial de quimioterápicos (JESUS-GARCIA et al., 1996).

O diagnóstico diferencial deve ser realizado para outros tumores ósseos primários, tumores ósseos metastáticos, osteomielites bacterianas e micoses sistêmicas (DALECK et al., 2002), para um tratamento adequado. O diagnóstico preciso de OSA só poderá ser realizado pelo histopatologista (DALECK et al., 2002) e esforços devem ser feitos para que o diagnóstico seja feito o mais precocemente possível (RECH et al., 2004), aumentando dessa forma o prognóstico e a sobrevida do paciente. 
Em relação ao tratamento, foi observado nos últimos 25 anos uma melhora significativa no prognóstico dos casos de OSA, especialmente naqueles com a doença localizada (RECH et al., 2004), direcionando um tratamento específico de acordo com a localização e o tamanho da lesão (LIMA et al., 2002).

Tradicionalmente o OSA era tratado exclusivamente por amputação ou desarticulação do membro envolvido (RECH et al., 2004; RUBIN; FARBER, 2002), porém mais da metade deles apresentava recidiva sistêmica da doença em menos de seis meses e $90 \%$ evoluíam para óbito devido sua progressão (RECH et al., 2004).

Na terapia Adjuvante, estudos com cães tem mostrado que a cisplatina usada sozinha ou em combinação com a dexorrubicina ou o lipossomo encapsulado com tripeptídeo muramil fosfatidiletanolamina, têm proporcinado resultados satisfatórios aumentando a sobrevida (DALECK et al., 2002).

Outros trabalhos têm sugerido que não há diferença na sobrevida livre da doença entre a cirurgia imediata seguida de quimioterapia adjuvante e pré-operatória, porém recomendase sempre que possível que o paciente seja submetido à cirurgia após o uso de quimioterapia, permitindo que pacientes que repondam bem à quimioterapia se beneficiem do tratamento cirúrgico conservador (RECH et al., 2004).

A efetividade da quimioterapia neoadjuvante pode ser determinada pela porcentagem de necrose tumoral no fragmento ressecado (RECH et al., 2004); se essa porcentagem for baixa a resposta quimioterapica é considerada inadequada, sendo recomendado um protocolo mais agressivo no pós-operatório (DALECK et al., 2002).

Outro tipo de tratamento sistêmico é o uso de bifosfonatos, que inibem a reabsorção óssea pelos osteoclastos, dificultando a implantação de células tumorais nos ossos, tendo uma ação profilática (CAMARGO; BAPTISTA, 2004, JARK et al., 2013). Além do uso em OSAs apendiculares, os bifosfonatos podem ser úteis no tratamento dos OSAs axiais, mielomas múltiplos, metástases ósseas e controle da hipercalcemia maligna em determinados casos (JARK et al., 2013). A radioterapia também pode ser usada nas partes moles, para diminuir ou eliminar a dor, tendo uma ação direta na lesão, diminuindo seu tamanho e sua extensão (CAMARGO; BAPTISTA, 2004). 
Em cães a amputação é um tratamento tradicional, porém apesar do alivio do desconforto local, raramente essa modalidade resulta em cura, sendo que o tratamento cirúrgico deve ser considerado paliativo quando realizado isoladamente (DALECK et al., 2002). A principal vantagem da amputação nos cães é a ressecção completa do tumor primário e o alivio da dor (DALECK et al., 2002).

Andrade (2008) descreve um estudo de caso onde a paciente foi submetida à intervenção cirurgica do membro pélvico esquerdo, na região mesofemoral, devido ao fato de não haver comprometimento da parte distal do fêmur, apresentando uma recuperação rápida e sem complicações.

Segundo estudos, em alguns pacientes submetidos à amputação não ocorreu reincidiva local, mas um grande número deles evoluiu para metástase pulmonar (JESUS-GARCIA et al., 1996). No Brasil, existe um grande número de proprietários que não autoriza a amputação do membro afetado. Isso impossibilita que o clínico veterinário realize a terapia mais adequada, reduzindo a qualidade de vida e consequente sobrevida do paciente (ZILIOTTO et al., 2003).

Na cirurgia com preservação do membro do OSA é importante avaliar a extensão óssea e as partes moles do tumor com o objetivo de obter a ressecção com margens livres e amplas (CASSONE, 2005; JESUS-GARCIA et al., 1996), assim como a preservação da função do membro sempre que possível, dentro dos critérios oncológicos (JESUS-GARCIA et al., 1996).

Embora se preconizem margens amplas, as regiões marginais também são adequadas em pacientes que respondem bem à quimioterapia neoadjuvante (necrose acima de 90\%), podendo dessa forma preservar estruturas anatômicas importantes na reconstrução e obter um melhor resultado funcional (CASSONE, 2005).

\section{CONCLUSÃO}

Cães de grande porte e gigantes apresentam uma predisposição ao desenvolvimento de OSA apendicular em animais com idade entre cinco e oito anos, com peso superior a trinta quilos com uma prevalência em indivíduos do sexo masculino. O OSA é um tipo de tumor ósseo 
que causa considerável número de mortes, assim um diagnóstico correto e um tratamento apropriado pode melhorar consideravelmente a sobrevida desses pacientes, levando ao declínio dos índices de mortalidade que vêm sendo observados. Estudos demonstram que em muitos casos, os proprietários de cães com OSA desistem do tratamento, acarretando em maior sofrimento para o animal.

Em animais com muitas metástases e baixa qualidade de vida, a eutanásia é indicada com permissão do proprietário. O tratamento do OSA está bem determinado em ossos longos, mas pouco compreendido quando essa patologia afeta a mandíbula ou a maxila dos individuos, necessitando de maiores estudos nesta área e uma maior padronização dos protocolos de quimioterapia visando uma maior eficiência da terapia.

A importância dos estudos de OSAs em cães vem aumentado com o favorecimento de uma progressão no tratamento das neoplasias ósseas em humanos devido às semelhanças de parâmetros biológicos e histopatológicos, resposta a moléculas quimiocitotóxicas, dentre outros fatores.

\section{CLINICAL AND PATHOPHYSIOLOGICAL ASPECTS OF OSTEOSARCOMA IN DOGS}

\section{ABSTRACT}

$\mathrm{T}$ he osteosarcoma (OSA) is a malignant bone tumor characterized by the formation of neoplastic bone tissue with rapid and invasive growth. Among primary bone tumors OSA is the most common due to the proliferation of primitive mesenchymal malignant cells and the production of osteoid matrix. Its etiology remains unknown, but there is evidence of OSA development into higher weight bearing bones and adjacent sites of late closure through cellular sensitization by mitogenic factors, previous sites related to metallic orthopedic implants, ionizing radiation, genetic mutations and viral infections. The diagnosis is based on the clinical history of the animal, physical examination, imaging and histopathology. Recent treatments are based on chemotherapy and member sparing surgeries where the animal has a more favorable prognosis. This paper presents a review of the literature on clinical and pathophysiological aspects of OSA in dogs. For the composition of the literature review a research was conducted in the databases SciELO and Periódicos da Coordenação de Aperfeiçoamento de Pessoal de Nível Superior (CAPES). National and international scientific articles and academic books were researched in Scholar Google. OSA causes a considerable number of deaths, so a correct diagnosis and appropriate treatment 
can improve the survival of these animals, leading to the decline in mortality that is being observed.

Keywords: Osteosarcoma. Dogs. Tumor. Treatment.

\section{ASPECTOS CLÍNICOS Y FISIOPATOLÓGICOS DEL OSTEOSARCOMA EN PERROS}

\section{RESUMEN}

$\mathrm{E}$ I osteosarcoma (OSA) es un tumor óseo maligno caracterizado por la formación de tejido óseo neoplásico con un crecimiento rápido e invasivo. Entre los tumores óseos primarios el OSA es la neoplasia más común debido a la proliferación de células malignas mesenquimales primitivas y a la producción de matriz osteoide. Su etiología es desconocida, pero hay evidencia de que los OSA se desarrollan en huesos que soportan mayor peso y sitios adyacentes de cierre tardío mediante la sensibilización celular por factores mitogénicos, sitios previos relacionados con los implantes ortopédicos metálicos, radiación ionizante, mutaciones genéticas y las infecciones virales. Su diagnóstico se basa en la historia clínica del animal, el examen físico, las imágenes y la histopatología. Tratamientos recientes son basados en la quimioterapia y cirugías ahorradoras de los miembros, donde el animal tiene un pronóstico más favorable. Este artículo tiene el objetivo la revisión de la literatura sobre aspectos clínicos y fisiopatológicos del OSA en los perros. Para la composición de la revisión fue realizado un levantamiento de información en las bases de datos SciELO, portal de periódicos de la Coordinación de Perfeccionamiento de Personal de Nivel Superior (CAPES), y la búsqueda de datos en Google Scholar, de artículos científicos nacionales e internacionales y libros académicos. OSA causa considerable número de muertes, por lo que un diagnóstico correcto y un tratamiento adecuado pueden mejorar la supervivencia de estos animales llevando a la disminución de la mortalidad que se viene observando.

Palabras clave: Osteosarcoma. Perros. Tumor. Tratamiento.

\section{REFERÊNCIAS}

ANDRADE, S. A. F. Osteossarcoma apendicular em tíbia: Relato de caso. Revista Unilus Ensino e Pesquisa, v. 5, n. 8, 2008.

BASTOS, T. M.; SERAFINI, O. A.; BARRIOS, C. H. E. ;VELASCO, P. A. Osteossarcoma: tratamentos e fatores prognósticos. Revista Brasileira de Ortopedia, v. 34, p. 59-62, 1999.

BRASILEIRO FILHO, G. Bogliolo Patologia. 6. ed. Rio de Janeiro: Guanabara Koogan, 2000. 
CAMARGO, O. P.; BAPTISTA, A. M. Conduta atual nas lesões ósseas metastáticas. Revista Brasileira de Ortopedia, v. 39, n. 6, p. 273-281, 2004.

CASSONE, A. E. Estudo da invasão da placa fisária pelo osteossarcoma: sua recuperação no prognóstico da lesão. Revista Brasileira de Ortopedia, v. 40, p. 638-644, 2005.

COSTA, F. S.; TOSTES, R. A.; FARIAS, M. R.; SAMPAIO, R. L.; PEREZ, J. A. Metástase cutânea de osteossarcoma em um cão - relato de caso. Brazilian Journal of Veterinary Research and Animal Science, v. 38, n. 5, p. 240-242, 2001.

COTRAN, R. S.; KUMAR, V.; COLLINS, T. Robbins Patologia Estrutural e Funcional. 6. ed. Rio de Janeiro: Guanabara Koogan, 2000.

DALECK, C. R.; FONSECA, C. S.; CANOLA, J. C. Osteossarcoma canino - revisão. Revista de Educação Continuada CRMV/SP, v. 5, n. 3, p. 233 - 242, 2002.

DAVID, A.; RIOS, A. R.; TARRAGO, R. P.; ABREU, A.; DORSCH, A. C.; ALBERTI, S. Z. Osteossarcoma periosteal: estudo de quatro casos. Revista Brasileira de Ortopedia, v. 38, n. 10, p. 223-232, 2003.

ETTINGER, S.; FELDMAN, E. C. Tratado de Medicina Interna Veterinária - Doença do cão e do gato. 5. ed. Rio de Janeiro: Guanabara Koogan, 2000.

JARK, P. C.; NARDO, C. D. D.; BERNABÉ, C. G. et al. Emprego dos bisfosfonatos em oncologia veterinária. Veterinária e Zootecnia, v. 20, n. 3, 2013.

JESUS-GARCIA, R.; CONSENTINO, E.; CAMARGO, O. P.; BAPTISTA, P. P. R.; CROCI, A. T.; KORUKIAN, M.; KECHICHIAN, R.; PETRILLI, A. S. Tratamento ortopédico do ostessarcoma. Revista Brasileira de Ortopedia, v. 31, n. 11, p. 871-878, 1996.

KLEINER, J. A.; SILVA, E. G. Tumores ósseos em pequenos animais. Medvep, v. 1, n. 3, p. 193200, 2003.

KUMAR, R. V.; RAO, C. R.; HAZARIKA, D.; MUKHER-JEE, G.; GOWDA, B. M. Aspiration biopsy cytology of primary bone lesions. Acta Cytologica, v. 37, n. 1, p. 83-89, 1993.

LIMA, M. A.; RIVAS, L. G.; GRECCO, M. A. S.; DRUMOND, J. M. N. Osteossarcoma extraesquelético primário da região frontal. Revista de Assistência Médica Brasil, v. 44, n. 1, p. 43-46, 1998.

LIMA, J. J. G.; MANZI, F. R.; SILVA, F. L.; BAPTISTA, M. Z. Osteossarcoma extra-esquelético na região cervical - revisão da literatura e relato de caso clínico. Radiologia Brasileira, v. 35, n. 5, p. 315-319, 2002. 
MARTELLI, A.; TEIXEIRA, L. B. C.; SANTOS JR, A. R. Aspectos histopatológicos e histoquímico de osteossarcomas em cães. Estudos de Biologia: Ambiente e Diversidade, v. 29, n. 67, p.179-189, 2007.

MENDES, W. L.; GRAÇA, A.; CAMARGO, B. Locais incomuns de metástases do osteossarcoma: relato de nove casos de uma mesma instituição. Revista Brasileira de Ortopedia, v. 39, n. 6, p. 300-307, 2004.

MEUTEN, D. J. Tumors in Domestic Animals. 4. ed. lowa: lowa State Press, 2002.

MOORE, A. S. Osteosarcoma in dogs: managing a destructive disorder. Veterinary Medicine, v. 96, n. 7, p. 539-546, 2001.

NELSON, R. W.; COUTO, C. G. Medicina Interna de pequenos animais. 2. ed. Rio de Janeiro: Guanabara Koogan, 1998.

RECH, A.; CASTRO Jr. C. G.; MATTEI, J.; GREGIANIN. L.; DI LEONE, L.; DAVID, A.; RIVERO, L. F.; TARRAGO, R.; ABREU, A.; BRUNETTO, A. L. Características clínicas do osteossarcoma na infância e sua influência no prognóstico. Jornal de Pediatria, v. 80, n. 1, p. 65-70, 2004.

RUBIN, E.; FARBER, J. L. Patologia. 6. ed. Rio de Janeiro: Guanabara Koogan, 2002.

SHONUBI, A. M.; AKIODE, O.; SALAMI, B. A. ; MUSA, A. A. ; NTELE, L. M. A preliminary report of fine-needle aspiration biopsy in superficially accessible lesions in children. West African Journal of Medicine, v. 23, n. 3, p. 221-223, 2004.

SILVEIRA, L. M. G.; CUNHA, F. M.; BIASI, C.; SILVA, P. T. D.; KOLBER, M.; FERRIGNO, C. R. A. Osteossarcoma extra-esquelético no tecido subcutâneo de um cão: relato de caso. Revista Clínica Veterinária, v. 64, p. 89-90, 2005.

SIQUEIRA, V. J. W.; CAVALCANTI, J. N. Osteossarcoma pós-fratura umeral em um cão - relato de um caso. Revista Cães \& Gatos, v. 8, n. 42, p. 04-06, março/abril, 1993.

SOARES, R. C.; SOARES, A. F.; SOUZA, L. B.; SANTOS, A. L. V.; PINTO, L. P. Osteossarcoma de mandíbula inicialmente mimetizando lesão do periápice dental: relato de caso. Revista Brasileira de Otorrinolaringologia, v. 71, n. 2, p. 242-245, 2005.

STRAW, R. C.; WITHROW, S. J.; POWERS, B. E. Management of canine appendicular osteosarcoma. Veterinary Clinical of North American: Small Animal Practice, v. 20, n. 4, p.1141-1161, 1990.

TEIXEIRA, L. V.; MARTINS, D. B.; FIGHERA, R.; LOPES, S. T. A. Estudo clínico de osteossarcoma canino. Acta Scientiae Veterinariae, v. 38, n. 2, p. 185-190, 2010. 
TOSSATO, P. S.; PEREIRA, A. C.; CAVALCANTI, M. G. P. Osteosarcoma and chondrosarcoma radiographic differentiation by means of computed tomography. Pesquisa Odontológica Brasileira, v. 16, n. 1, p. 69-76, 2002.

WITTIG, J. C.; BICKELS, J.; PRIEBAT, D.; JELINEK, J.; KELLAR-GRANEY, K.; SHMOOKLER, B.; MALAWER, M. M. Osteosarcoma: A Multidisciplinary Approach to Diagnosis and Treatment. American Family Physician, v. 65, n. 6, p. 1123-1132, 2002.

ZILIOTTO, L.; FANTINATTI, A. P.; DALECK, C. R.; PADILHA FILHO, J. G.; SOUZA, A. P.; DINIZ, P. $P$. V. P. Utilização de implante ósseo cortical alógeno conservado em glicerina para preservação de membro torácico: estudo experimental em cães. Acta Cirurgica Brasileira, v. 18, n. 2, p. 107-115, 2003.

Autor para correspondência: Anderson Martelli. Rua Duque de Caxias, 229, Centro, Itapira - SP. CEP 13974-345. martellibio@hotmail.com 